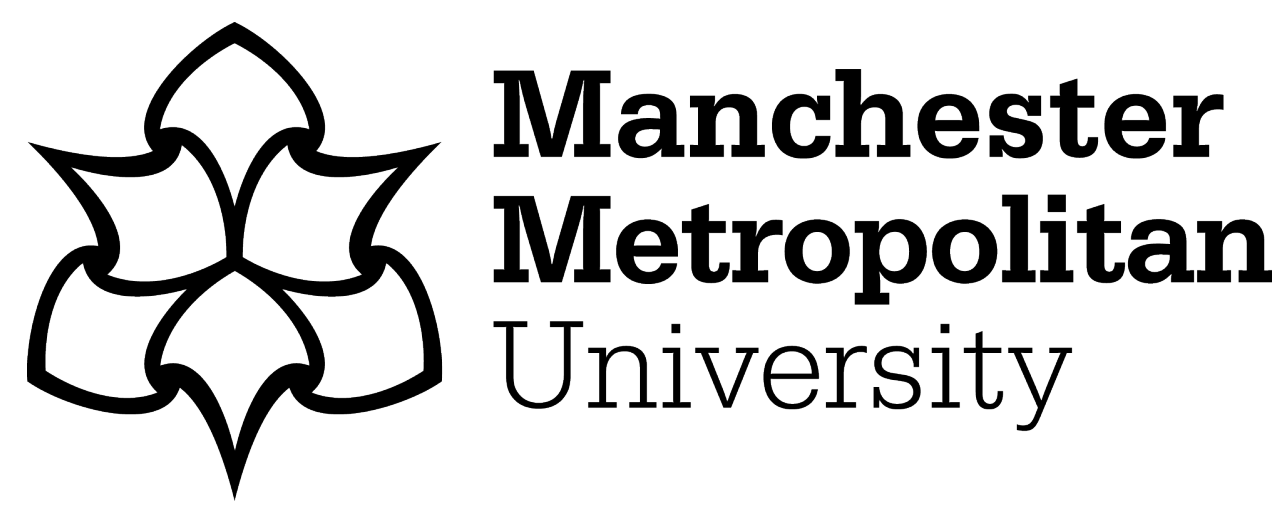

Solomon, Y ORCID logoORCID: https://orcid.org/0000-0002-2731-8380 and Lewin, C ORCID logoORCID: https://orcid.org/0000-0002-3430-4075 (2016) Measuring 'progress': performativity as both driver and constraint in school innovation. Journal of Education Policy, 31 (2). pp. 226-238. ISSN 02680939

Downloaded from: https: //e-space.mmu.ac.uk/583948/

Version: Accepted Version

Publisher: Taylor \& Francis (Routledge)

DOI: https://doi.org/10.1080/02680939.2015.1062147

Please cite the published version 


\title{
Measuring 'progress': performativity as both driver and constraint in school innovation
}

\author{
Yvette Solomon and Cathy Lewin
}

Education and Social Research Institute, Manchester Metropolitan University, Manchester, UK

Corresponding author: y.solomon@mmu.ac.uk; Education and Social Research Institute, Manchester Metropolitan University, Brooks Building, Birley Fields Campus, 53 Bonsall Street, Manchester, M15 $6 \mathrm{GX}$

Yvette Solomon is professor of education in the Education and Social Research Institute, Manchester Metropolitan University, and professor II in mathematics education at Oslo and Akershus University College of Applied Sciences, Norway. Her main research interests concern the development of learner identities within STEM subjects from primary years through adulthood, and teachers' professional development within mathematics education policy contexts.

Cathy Lewin is professor of education in the Education and Social Research Institute, Manchester Metropolitan University. Her research interests concern the use of technology to support educational change in schooling and young people's use of technology in formal, nonformal and informal settings. She has more than 15 years' experience of evaluating technology use in schools for both the UK government and the European Commission.

\footnotetext{
Abstract

In this paper we describe one secondary school's radical attempt to re-think the shape and purpose of education for its pupils, and its subsequent return to more traditional methods in the face of pressures of performativity and accountability. Framing our analysis within Activity Theory and its emphasis on contradiction as a driver for change, we describe the school's move towards a thematic curriculum and 'personalised learning' as a process of productive tensions which enabled the development of new approaches to education. While these innovations were considered to be of major benefit to both teachers and pupils, a fundamental contradiction between the focus on individual development underpinning the new approach and the demands of accountability in a persistent
} 
culture of performativity proved to be insurmountable. We argue that this particular contradiction highlights the dominance of measurability in judgments of school success and individual progress, with consequences for the pupils' longer-term education futures.

Keywords: curriculum innovation, activity theory, performativity

\section{Introduction: re-envisioning education within the personalised learning policy landscape}

This paper examines one school's attempt to implement a radical change in young people's educational experiences through a reorganisation of its curriculum and pedagogic approach. Initially driven by a mix of policy initiatives introduced by New Labour including personalised learning (Leadbeater 2006; Maguire, Ball, and Braun 2013; Miliband 2006), greater flexibility in the English National Curriculum (Whitty 2010), and the Building Schools for the Future programme (DfES 2004), the redesign of the school led to a number of challenges which were perceived by staff as positive. However, these initiatives were also embedded in New Labour's continuation of, and increasing emphasis on, the neoliberal agenda of accountability in education (Ranson 2008), a duality which persisted with the Coalition Government after 2010 in terms of 'Big Society' individual empowerment alongside increased focus on outcomes measurement (Ridell 2013). Performance measures ultimately led to a fundamental contradiction between the school's new goals for education and those of the wider policy context, with a consequent judgement of failure and a complete reversal of the changes. Focusing on the perspectives of teachers and managers at the time of transformational change, this paper explores how this complex policy landscape led to tensions and contradictions within and between educational systems (Engeström 1999; Brown and Cole 2002); in particular, it reveals the part played by performativity and 
accountability in constraining change, through the dominance of measurability in judgements of school success and individual progress.

The secondary school on which this case study focuses is located in the North of England, in an area of former heavy industry which at the time had high levels of unemployment and was one of the most deprived areas in the country. Under the same leadership since the mid-1990s, the school had already improved its provision at Key Stage 4 (KS4, education for 14-16 year olds) and its overall results were on an upward trend with $81 \%$ of pupils achieving $5 \mathrm{~A}^{*}$ to $\mathrm{C}$ at GCSE (public examinations taken at age 16) in 2007, although if English and mathematics are included this figure was $37 \%$ (compared to the national average of $46 \%$ at the time). However, a whole school inspection in 2007 suggested that Key Stage 3 (KS3, education for 11-14 year olds) outcomes needed to be improved. Building on the development work at KS4, which included more flexibility and choice for students, and drawing on theories of independent and deep learning, the school set about rethinking education across its whole provision. Aiming for 'outstanding' status (through the school inspection process), the school management viewed 'radical' innovation as a means of achieving this.

As indicated above, the redesign of the school was underpinned by a number of national policies and initiatives which both acted as a catalyst for change and also provided opportunities to put ideas into practice. A major influence was the concept of personalisation of learning, which David Miliband, the then schools standards minister, was instrumental in developing and introducing into educational policy in 2004 (Hartley 2007). Hartley $(2007,634)$ stressed that 'a central aspect of personalisation is coproduction: that is to say, users [students] should become more active and more responsible in helping to deliver the service [education]'. The aim of personalised 
learning was to raise achievement through such individual responsibility: 'Personalised learning is the way in which our best schools tailor education to ensure that every pupil achieves the highest standard possible' (Miliband 2006, 24). Greater learner responsibility, or independent learning (Meyer et al. 2008), demands self-management of targets within a neoliberal framework of choice: 'Learners should be actively, continually engaged in setting their own targets, devising their own learning plans and goals, choosing from among a range of different ways to learn' (Leadbeater 2006, 111). The curriculum developments that took place around this time included reducing the prescribed subject content to provide more opportunities to support personalised learning and an increasing emphasis on cross-curricular links (QCA 2007; Whitty 2010). Embedded in the new curriculum was a framework of personal learning and thinking skills for learners (independent enquirers, creative thinkers, team workers, selfmanagers, effective participators, and reflective learners).

The UK 'Building Schools for the Future (BSF)' capital investment programme was launched in February 2003 (DfES 2004). It was ostensibly designed to transform educational practices and learning spaces through investment in buildings and ICT infrastructure, with an original budget of $£ 45$ billion. Although the aims of BSF were not clearly articulated and indeed presented differently by various stakeholders (Mahony, Hextall, and Richardson 2011), it was related to educational reforms which aimed to support innovation and raise standards, running alongside policy initiatives such as personalised learning. Indeed, the BSF programme was closely intertwined with the personalised learning agenda. The Gilbert review (2006), commissioned to envision how personalised learning and teaching might be in 2020, recommended the design of flexible, familiar and welcoming learning spaces that would facilitate participation and collaboration, support knowledge sharing between teachers, and employ technology. 
The radical transformation of the school considered here was also influenced by a series of pamphlets by David Hargreaves during the period 2004-8 (eg Hargreaves 2004; Hargreaves 2006; Hargreaves 2007) on personalising learning, the ‘deeps’ (deep learning, experience, support and leadership) and system redesign produced for the Specialist Schools and Academies Trust ${ }^{1}$. The increased flexibility in the National Curriculum for English secondary schools and the funding available from BSF provided opportunities to realise the vision. The school began to implement changes moving towards a project-based thematic curriculum, a strong reliance on technology, major spatial change towards 'mini schools' (also known as the school-within-school model) and shared open spaces, and student self-management of learning. As a BSF test bed project, the school received in the region of $£ 1$ million pounds initially to build and resource a different learning space to facilitate this new approach. During the summer of 2008 a temporary building was erected and, in September, the first cohort of Year 7 students began to experience the re-designed teaching and learning approaches. At the time of the study reported here, the curriculum innovation was in its third year and involved learners aged 11 to 14 years, who were organized into three mixed-age minischools. Together with a redesign of the learning spaces, the delivery of the curriculum was transformed. Instead of all students following a traditional timetable, moving from room to room to be taught in traditional 50-minute lessons by subject specialist teachers, students elected how to spend their time, booking in to 15-minute subject tutorials in addition to their independent study. Teachers in the mini-schools were expected to be expert in their subject but also to provide general support to the students

\footnotetext{
${ }^{1}$ The Specialist Schools and Academies Trust was a non-profit organisation providing continuing professional development and support for schools in England and internationally. It became a private company in 2012.
} 
working independently within a single, large space. The new (and developing) system adopted to achieve this included redefining the role of the teacher, the integration of ICT into teaching and learning, the development of new assessment practices including student progress tracking technology, and pedagogical shifts.

\section{Theoretical framework: understanding processes of innovation and performativity within competing systems}

The 1988 Education Reform Act in England and Wales introduced a quasi-market into the state education system whereby schools were directly funded according to their pupil numbers, which were dependent on parental choice. Competition between schools - intended to drive up standards - led to an emphasis on promotion (see Gewirtz, Ball, and Bowe 1995), fuelled by further reforms in the early 1990s which made individual schools' examination results public in 'league tables' in addition to Ofsted inspection reports (Exley and Ball 2013). The public nature of these measurement systems, particularly the role played by examination results in high stakes inspection outcomes and league tables, has a far-reaching impact on how schools behave. Performativity (Ball 2003) is described as a technology of reform which not only leads to change at organisational level but also changes 'what it means to be a teacher' (217), an observation with particular relevance here given how the school's new approach positioned teachers. Ball (2003) argues that whilst the mechanisms of performativity - target setting, school inspections, school league tables and performance management systems (Perryman 2006; Troman 2008) - are presented as a means of shifting the locus of control from the state to organisations (schools), performativity is in fact re-regulation or hidden regulation through 'management panopticism' rather than deregulation. Hence, 'performativity is linked with the increased accountability and 
surveillance under which teachers find themselves and their schools being judged in terms of outcome and performance' (Perryman 2006, 150). Moreover, there is a constant pressure for improvement such that educators are 'continually accountable' (Ball 2003). Measuring, monitoring and improvement have become embedded and normalised in school cultures (Ball and Olmedo 2013; Keddie 2013), impacting on how teachers 'are able to be in their classrooms and their schools' (Ball and Olmedo 2013, 88). Through performativity, schools are encouraged to innovate both to 'raise achievement' and to provide a competitive edge.

Our focus on innovation and its progress and implementation within a whole school system led us to choose third-generation activity theory (Engeström 2001) as a means of teasing out the complexities of the policies at play. The central tenet behind activity theory is a need to consider an activity system as a whole - the social practices of a community in a specific context (Engeström 1987, 1999) - and thus it offers 'a framework for analysing a multitude of relations’ (Mørch, Nygård, and Ludvigsen 2010, 187). It expands on Vygotsky's theory of mediated object-oriented behaviour (1978) by incorporating rules, community and division of labour into the analysis, and also focuses on interactions between multiple co-existing and overlapping activity systems. Activity theory, therefore, provides a lens on the overall collective activity of the school, its separate elements, and its interactions with other systems such as the local schools market or the wider policy context. It captures how individuals within the system work in accordance with its rules (implicit and explicit regulation, norms and values), division of labour (teaching, managing, coaching, supporting roles), and tools and artefacts (particularly ICT-based, in this case) in the service of a common object educating its students to become independent, motivated and choice-making learners. 
It also captures how the system interacts with other systems: in addition to the local focus on independent and self-motivated learning there was (and still is) an overarching objective in the wider school system in the UK of 'raising achievement' - defined in terms of summative assessment, specifically GCSE results. Thus we can understand the workings of the school within the wider market and policy context in terms of the relationship between its local norms and values and those which operate at a national level, such as accountability measures. Analysing the situation in terms of interacting activity systems draws attention to the particular tensions or contradictions which arise between these local norms and those of a culture of performativity in which 'the performances (of individual subjects or organizations) serve as measures of productivity or output, or displays of "quality", or “moments” of promotion or inspection' (Ball 2003, 116). As we shall show, the force of GCSE results as a single marker of learning outcome or 'output' was - with hindsight - evident in the early stages of the school's reinvention of itself, exerting an almost inevitable influence on the eventual outcome in terms of a contradiction between systems. Indeed, as we shall suggest, the final outcomes of our narrative can be seen in Perryman's $(2006,148)$ terms as a product of a regime of 'panoptic performativity' in which 'frequency of inspection and the sense of being perpetually under surveillance leads to teachers performing in ways dictated by the discourse of inspection in order to escape the regime'. While the school did not neatly fit Perryman's description of such a school (for example, prescribed teaching practices, a narrow focus on passing inspection), its departure from rigidity in terms of the curriculum and pedagogy, and its focus on education as supporting autonomous development were in tension with other aspects of its practice, particularly monitoring of student progress and target-setting not only as a means of support for independent learning, but also - and less overtly - as important in the shadow of GCSE 
benchmarking. Activity theory provides a lens through which we can see the workings of these tensions, as the schools' collective pedagogic beliefs are enacted in accordance with rules and divisions of labour which are supported by, but also ultimately subjugated to, a technology of student monitoring which serves another object.

Contradictions play a central part in activity theory in terms of their role in the development of systems (Engeström 1987), and they are the focus of our analysis here. There are multiple contradictions at play in the education system: between the use and exchange value of learning as intrinsically useful or interesting versus the currency of certain subjects and their related qualifications in the job market; between monitoring tools and the aim of student independence; between the new thematic curriculum structure and an exam-led subject-based curriculum; and between local (internal) pedagogic aims of producing 'the rounded student' and a focus on the measurable and league table success. Contradictions have a particular role in activity theory in explaining change processes, since an activity system is never considered to be a fixed entity but is always in a constant state of flux (Kuutti 1996). For Engeström, contradictions trigger change and 'expansive transformation', when individuals question the system and reconceptualise its object and motive in ways which 'embrace a radically wider horizon of possibilities than in the previous mode of the activity' (Engeström 2001, 136-137). In our particular case study, the innovation in question was clearly going to generate contradictions, as new structures, practices, tools and division of labour were introduced in accordance with the 'vision', radically transforming the school. Arguably, the school had attempted an expansive transformation of its educational provision; but, crucially, activity theory highlights that just instituting structural differences does not in itself produce change - this comes about through resolving the resulting contradictions as in Engeström's (2001) model of 
improving working practices through reflection on contradictory viewpoints, practices and values (see for example, Engeström 1999; Daniels 2008).

In what follows, we focus on the nature of change, and the part played by contradictions in the school's reinvention of itself, seen through accounts given at the time by the teaching and management staff, as the major implementers of change. In particular, we explore the ways in which the proposed radical transformation of the school's activity system impacted on divisions of labour and the use of performance tools, and the tensions and contradictions which existed both within the system and between systems.

\section{Methodology}

The school presented here originally requested an independent evaluation of their new educational approach at the time of its launch in 2008, and this was carried out by the second author, who not only produced a formal report but also sought and received permission from the school to write academic papers based on the findings. As the school's plans were ambitious and innovative we asked if we could return to see how things were progressing two years later in order to follow up on the evaluation work and collect data with a view to applying for funding for further research. We listed a number of potential interests, including the school's cross-curricular approach, the change in teacher roles, student progression, the school's use of technology, and its relationships with Ofsted and parents. The data on which this paper is based were collected from March to May in 2011, including interviews with teaching staff and school managers (senior leaders A and B), focus groups with students, and observation. Due to the time lag between the original evaluation and permission to publish, and the new data collection, we applied for, and were granted, institutional ethical approval for 
publication based on the new data. Documentary evidence such as policy documents and external inspection reports were also gathered.

This paper is based on a total of eight interviews with the key players responsible for the implementation of change: senior leaders A and B; two teachers responsible for redesigning the curriculum across the school - the 'lead teacher of learning' and the 'subject consultant' (interviewed together); one teacher with subjectspecific responsibility for mathematics; and one teacher with the role of facilitating learning to learn - the 'learning coach'. With one exception, the interviews were open and unstructured, our aim being to gather data on individuals' roles and responsibilities, their accounts of how the school and their roles had changed, their perceptions of the challenges these presented for them and for the school, and projections into the future. As our main point of contact, senior leader A took particular responsibility for our visits, and our four interviews with him also reflected his interests to some degree; in particular, one revolved around a PowerPoint presentation in which he demonstrated the pupil performance tracking software that the school used. He took on a particular role in our visits of explaining the school vision and its implementation, in addition to describing his own personal role and perspective. Three other interviews were framed within the context of his introduction of the school, a discussion following up after we had looked around the school and had interviewed other staff and students, and a final wrap-up interview at the end of our visit. Clearly, this was a slightly unusual data collection situation given its background in the original evaluation work; we recognise that to some degree our interviewees might have been keen to present a positive story over and above the level that we might expect any teacher to present when asked about their work. We are of course unable to judge how far this was the case, but we draw attention to our overall theoretical framework which looks for contradictions and 
incorporates these into the analysis of the system as a whole, enabling a robust treatment of interviewees' presentations of their roles. As in any research context which involves changing systems, informants' comments are historically situated and may not be reflective of their later/current thinking ${ }^{2}$. All interviews took place in the school, and were audio-recorded with permission and fully transcribed. Individuals and the school itself are anonymised.

The interviews were initially analysed independently by the authors to identify emergent themes relating to individuals' roles and perceptions of the school, followed by a collaborative analysis to highlight any differences and similarities between interpretations. Subsequent analysis was organised around themes from activity theory, and identified the discourses drawn on by the various players in terms of the new object and how it was achieved, changes in the division of labour, and the use of tools within the context of the developing activity system. In particular, we looked for system tensions and contradictions, aiming to provide a detailed view of the nature of on-going change and the unfolding of the school vision of educational innovation. In what follows, we focus first on understanding the new system in terms of object and outcomes, division of labour, and rules and tools. Then we turn to an analysis in terms of the contradictions that arose within and around the new system, focusing on how such contradictions were related, experienced and addressed against the backdrop of ever-present performance measures.

\footnotetext{
${ }^{2}$ Senior leader A has made this point in particular, having read this article.
} 


\section{Analysis: innovation, contradictions and performativity}

\section{The innovation process: new rules, tools and division of labour in service of a}

new object of education

In this first part of the analysis, we describe the new school system in terms of what managers and staff told us about the changes, particularly in relation to the new object of the system and the new tools, rules and divisions of labour that supported it. The transformation involved new material structures, integration of ICT into the core functions of the school, the development of new assessment practices, and pedagogical shifts, which in turn led to the development of new mechanisms and rules, and new tools. The process of innovation necessarily produced contradictions - between old and new values, roles and relationships - the resolution of which was integral to its ongoing development, as we shall show in the second section of the analysis.

The object of the new system was the production of learning which had depth and relevance, built links between subjects, and was geared to students' needs - a 'rounded education' which also promoted both independent and personalised learning. This was most clearly expressed by senior leader A, whose account of the development of the school fleshes out what this meant in practice. Here he articulates the pedagogic philosophy behind it:

... you can make the areas more relevant ... it's a more functional approach to the subject areas in terms of making sure that they fit into where the student needs to be. What the student then does, we feel is, links the ideas across subject areas ... they don't see a Humanities volcano the same as a Science volcano normally. But by teaching them together, you can actually bring together all of that knowledge and cause the links to occur for a more rounded approach to education.

He argued that the benefits of this approach were illustrated by Year 9 students (aged 13-14) who had recently started a college course, with good reports about the ways in 
which they engaged in learning:

The testimony from the teachers there is that the readiness and willingness and ableness of our students to actually involve themselves in the learning process is far above what they're seeing from the other students, because it's what they've been programmed to do.

This shift in the object was supported by a change in individual teachers' pedagogic aims, as in the case of the learning coach, formerly a subject specialist teacher at the school but subsequently retrained to take responsibility for enabling students to act as independent learners. He told us that he no longer identified as a subject specialist, 'but more like a teacher of learning'. Continuing senior leader A's theme, he described how over the previous year this entailed a focus on 'how we can create a generic all-rounder and a better learner ... rather than just students that are strong in specific areas'.

Senior leader A explained further how the shift away from subject specialisms changed the pattern of teacher responsibility towards teaching in general rather than teaching subjects:

\footnotetext{
We still have teachers who have responsibilities for subjects but we are currently, whenever we appoint, ... We want to go down a route where we don't say 'this is your subject specialism' any more ... we'd love to ... generically advertise for teachers for children rather than teachers of Science or whatever. We'd love to go for that. ...
}

The mathematics teacher also focused on how her practice related to the new object of teaching. Although she had to plan carefully, integrating mathematics into the thematic projects gave it more meaning, and students 'could see the Maths, where you use it, how you use it...'.

One noticeable aspect of the new system was that relationships between teachers and 
students, and between teachers themselves, changed. The mathematics teacher believed that the new system worked because of its emphasis on students being more responsible for their own learning:

It gives the kids responsibility... they're responsible for their own time, organisation, you know, everything ... rather than just relying on adult and teacher and mum and dad.

The learning coach also noted how he knew students in a different way:

... When you're used to seeing them come in just for an hour, you thought you knew them, but you actually ... you didn't ... But as ... the learning coach, you have to ... get to know them inside and out, you have that familiarity with them, you know what makes them work and what areas they find quite difficult.

Developing the new object also required new working practices and the institution of a 'pedagogy team' that followed new procedural norms, as senior leader A explained:

What we did we had a learning community whereby we took the assistant head teachers who were involved and we said to them 'how do you want to develop this, what can we do?' That developed into having a team of people from assistant head teacher, lead teacher of learning and learning coach that we've put together. We decided that the best thing for them then was to actually look at different aspects of what we needed to develop so we've got one team that's working on ... the practical side of the subjects, we've got another team that are focusing on developing pedagogy and then we've got a third team that's focused on developing [cross-curricular] projects.

At teacher level, the learning coach told us how the whole team took responsibility for maintaining learning through the project system through, for example, more regular meetings. However, he also emphasised how creating the 'all-rounder' was not just a question of moving away from a subject focus to a cross-curricular approach, but also 
required the development of an independence which he described as largely managed by the performative mechanism of target-setting, highlighting an emerging contradiction to which we return below:

[Last year] they had targets and self-set methods of trying to integrate themselves into being effective group workers. So I did quite a lot of work with that, a lot of work with targeting, goal setting, time management ... I'd say that now they've started to think about ... what they have strengths in and what areas that they need a bit of development in.

The new division of labour in curriculum planning also came up in our discussion with the lead teacher of learning and the subject consultant, who both held management responsibility for the curriculum and its implementation:

We spoke to the learning community and we spoke to the heads of each department and we've ... well, we sort of came up with a list of possible project titles and then we ... invited all of the lead teachers to come and sort of sign up to the projects. And then it was their responsibility to make sure that the National Curriculum had been covered within the projects. ... And it's just been carefully mapped, [senior leader A] mapped everything out just to make sure that it's all ... it's all covered across the two years.

What is noteworthy here is their concern less with deep, connected learning and independence, but with coverage of the National Curriculum, appearing here as an external mechanism of control in Perryman's (2006) sense rather than change being driven by the pedagogy of student-centred learning. Unsurprisingly, they had an eye on the external activity system of curriculum policy, positioning themselves alongside senior leader A teacher within the division of labour in this regard. We return to the contradictions between aims which this indicates in section three of the analysis, where we will argue that the culture of performativity undermined the potential for lasting 
transformation.

\section{Towards 'expansive transformation'? The role of contradictions}

In this second section of the analysis, we look more closely at the development of the system in terms of responses to unfolding contradictions between the school's new norms, values and practices and those which underpinned the wider policy context, and in particular its emphasis on accountability measures. We will suggest that although much of the school's development was the outcome of positively transformative contradictions, a consciousness of ongoing inspection and surveillance created contradictions which could not be resolved within the new system.

Both senior leader A and senior leader B talked about how the school had developed since the inception of its reinvention, and how they continued to learn as a result of their recognition of contradictions between historical assumptions about teaching and their new object for the school. As senior leader B noted, ongoing questioning of the status quo was a major driver in developing a pedagogy which he termed 'transformational':

And why do we teach music for an hour? Why do we do that? Cos there's no logical reason for it. And it's sort of asking the same questions that we asked three or four years ago. ... we were asking questions about teacher learning... and asking some quite radical questions of them, for example, why do we teach people by their birthday. And actually they agreed with every single one of the radical options on the table and said well there is no good reason apart from socialisation. ... And so it's asking exactly the same radical questions now...

Senior leader A described how the object of independent learning took time to develop as the school learned from experience and adjusted its use of space and mode of curriculum delivery in quite fundamental ways in terms of students' and teachers' roles 
in the learning process:

We very quickly came on to the idea that the input was probably one of the least important parts of the learning process for the students and that actually the communication and the educational dialogue [that] takes place when a student and a teacher, or a student and a group of teachers sit together is far more powerful and far more useful.

Recognising how assumptions about teaching as 'input' ran counter to their vision of 'the rounded student', they thus departed from the traditional lesson format altogether in order to promote a very different positioning of the students as autonomous and responsible for their part in the process in a flipped learning model (Hamdan et al. 2013):

Staff are starting to realise that actually the input can be done differently. Some staff are trialling a system whereby they're actually recording their input and what the students are doing is actually getting that key input and then coming to a discussion forum.... where the students have to be prepared and come into that tutorial prepared. They've still got 15 minutes to discuss but the teacher's actually in there engaging with the students in the learning process as a team.

As these accounts suggest, the transformation of the school had in large part been the positive product of ongoing contradictions and discussion, as Engeström's conception of expansive transformation underlines. The school engaged in many debates about pedagogy, and these were still ongoing as they worked through the object of developing a cross-curricular approach. The thematic curriculum and its mode of delivery presented considerable challenges to teachers who had been trained in specific subject pedagogy and had experience dominated by this traditional approach. Nevertheless, the mathematics teacher believed that the tension between a thematic curriculum and subject coherence was worth grappling with: 
it's time-consuming, I mean when I did the war project, the war was the difficult one, ... just to phrase it to the war because you've got to keep the same Maths question, you know, like you've got to use the Maths in the proper way. So when you do it, phrase it to the war jargon, you've got to be careful not to affect the Maths things, so that's ... difficult ... but it's brilliant when we use [mathematics embedded in navigation], it worked really well...

Although the thematic curriculum and the object of the activity were well aligned, there were further contradictions in the system as teachers with different personal histories encountered the new division of labour and its object. But these were generally seen as presenting positive opportunities for reflection and growth; the lead teacher of learning commented that a major change in the teachers' role was relinquishing control over student learning (Hartley 2007; Leadbeater 2006), and this was difficult from the point of view of their teaching histories:

learning to let go and not wanting to have complete control over what the students are doing, you know, understanding that, actually, they are okay to work, to go and do that, because they've planned it and they want to do it and that's fine. And I think that's one of the biggest ... the biggest learning curves, to be honest.

Senior leader A also noted that this shift was difficult for some teachers:

... I think we've been on a shift in terms of the way that our school's changed its curriculum over long periods of time, so not just over the last three years. And I think ... one of the things that more traditional teachers may well have struggled with in terms of coming into this model is that blurring of that boundary in terms of who's the teacher, who's the learner.

Such contradictions appeared to be largely positive. However, the presence of an overarching contradiction between the school's internal aims (student as autonomous and deep learner), and the accountability measures emphasised in the wider policy system (resulting in a need to measure and monitor performance) exerted an on-going 
historical effect with consequences for both the transformation of the school and the final outcome. In particular, there were signs of less productive contradictions concerning 'failure' in the teaching system, which we discuss next.

\section{Unproductive contradictions: tracking and attainment}

Further tensions emerged from the discussion with the lead teacher of learning and the subject consultant; while both were, as we have seen, enthusiastic about the new division of labour and object of the cross-curricular delivery, their talk included multiple references to the 'old system' object of raising achievement as measured via the performative technology of summative assessment. The main aim of the lead teacher of learning role was to enhance progress and attainment, which introduced a major contradiction in terms of a disjunct between the emphasis on summative assessment through examination and the school's more recent focus on formative assessment and learning to learn. This contradiction between the reinvented school's system of values and division of labour in pursuit of its 'rounded student' object and the accountability measures of the wider policy system was unresolved; in particular, a panoptic performativity (Perryman 2006) was visible in the school's response to pressure to show measurable 'progress' within an externally specified time frame:

Yeah, student progress and attainment, I oversee that for the different subject areas and between myself and [the subject consultant], we'll come up with action plans for subject areas that might be appearing to perhaps not be making the progress that's necessary.

The performance tracking technology, explicitly employed as a means of measuring and monitoring (Ball and Olmedo 2013), was seen as an essential tool in the new system, and the learning coach made specific reference to it as a support for his role: 
I'm made aware relatively quickly ... that if students are in the green on the report [working below target level], we can see that if they're in green in a variety of subjects, we pick it up straight away. And so I will go round and speak to subjectspecific staff and, you know, see what areas they need to be working on and then you tend to identify a bit of a pattern going on as to why certain things are happening.

Monitoring in this way was described as fundamental to achieving the object of independent learning and self-management, although its actual employment potentially undermined learner autonomy and control. Senior leader A introduced it as giving students ownership of their own learning:

Use a principle of a pilot who's guiding a plane, at the start of a flight, before they take off, they know where they're going and they're know where they're starting from. Well our model, if you like, in learning, is that students and staff should be fully aware of that as well.... And so that kind of gives the students some ownership of what they're going to do.

In contrast to the learning coach's account of how he used the tracking technology to enhance students' independence, and senior leader A's account of giving students ownership, the subject consultant described how the tracking technology also operated at managerial level as a tool to review how teaching was going:

[The lead teacher of learning] has to have all of the data from each teacher which says which students are slightly under-performing, she analyses that and then we come up with an action plan. So within two days of ... you know, the reports [to parents] going out, we're already speaking with the teachers of that subject area and saying 'Right, what are we going to do and how can we improve this by the next few weeks when the reports go out?'

The discourse of 'progress' thus became linked to teachers' performance. The lead teacher of learning and the subject consultant described this system as enabling them to 
make pedagogic judgements "to identify groups that need different learning strategies and maybe slightly different courses", and to check whether a project was working out. However, it is noteworthy that this account was immediately preceded by mention of the three-weekly reports to parents - it was these reports that need to be improved by taking action:

... maybe half of the reports come back with a reply slip and they actually just say 'Oh yeah, absolutely fantastic, we're thrilled' or 'We're a little bit concerned about English' so we get the English teacher to phone the parent and say 'Look, you know, this is what we're doing to try and help them and this is where they should be, you know, in this next report' so ... because we put an extra intervention in for the students that aren't making the right progress..... we can always reassure them that something is in place if, you know ... certainly if they get a report where it doesn't appear that the progress has been made, it's good to reassure them that actually, something is being done.

It is notable that the student as independent and autonomous learner has become invisible in this passage, as contradictory aims of measurement and accountability, already embedded within a culture of performativity, take over. The dominance of discourses of coverage, levels and summative assessment was also evident in the interview with the mathematics teacher, in which she focused on covering the syllabus, differentiation, and levels, and the benefits of the 15-minute tutorials in terms of providing her with more time to target particular students to improve their grades.

Similar contradictions became apparent during our discussion with senior leader B, stemming from our initial questions about the benefits of the small number of pupils in the mini-school (around 120) and the 'family groups' mix of years 7 to 9. While he initially responded in terms of the pedagogic and pastoral benefits, he rapidly shifted to an emphasis on how the flexibility of this mix meant that student learning could be 
accelerated (thus raising overall achievement scores):

It also means, from an academic point of view, that that student in Year 7 who's sailing away can be taught with Year 8/Year 9. We've got Year 8 students doing Key Stage 4 BTEC courses.... They'd sailed through Passport, excellent, right let's get you onto another course, but of course they can do that alongside students in Year 9 cos we've just got total flexibility.

More followed regarding the possibility of supporting lower-attaining students, or those whose performance was patchy; he argued that the family system together with flexibility of study meant that students would not suffer the stigma of working at a level below the norm for their year group. However, he framed this within a context of technologies of monitoring, targets and interventions:

If you're somebody who's brilliant at assessment focus 1, 2, 3, 4 but not 5 we can target that. We can see where that gap is and we can put in place the necessary intervention to make sure that gap is made up.

There was, then, a fine line between formative assessment supporting independent, personalised learning, and surveillance in service of the need to perform in terms of cruder, more easily measured outcomes. The tension between these two appeared to be ever present, partly due to the inertia of pre-existing practices, but, as we argue in the next section of the analysis, as a result of unresolvable contradictions which placed the school under pressure to continue to account for itself in terms of straightforwardly quantifiable and recognisable student outcomes.

\section{The dominance of performativity}

The tension between innovation and competition arising through performativity and accountability, and the ultimate regulation of schooling is, we argue, clearly evident in our study of this highly innovative school, and the fundamental contradiction that it 
embodies is central to the final outcome. A major issue that emerged from the data is the extent of change that was required to fully enact the re-envisioning process - in Engeström's terms, transformational learning is an outcome of working through contradictions, and is not something which is achieved through structural changes alone. The process of innovation worked against the flow of accountability demands for visible results framed within existing summative measures. Staff (and students) were constantly aware of the ultimate GCSE outcomes benchmark, even though this was still two years away for Year 9, the first cohort of students in the new model. Thus, summative measurement ('numbers') was exerting power in the activity system and facilitating government at a distance (Piattoeva 2015). More immediately, inspection loomed; here senior leader A talks about what an inspection would ideally look at: ... we would predominately look at the learning that takes place ... we would be looking at how the staff member relates to managers, the [open learning] area and how the subject is progressing within that. ... a lot of our observations are focused on data in terms of assessment and progress and the assessment for learning that needs to be evident within books or online, however the assessment is taking place. ... the engagement of the students within the system is one of the key drivers and key indicators as to the progress that is being made.

But he was concerned that an inspection might miss what the school was doing in terms of changing the nature of learning and student engagement:

Should an OFSTED inspection team just be dropped in, parachuted into there and not be given any guidance or help in terms of understanding and appreciating where we're taking the [school] model, then we feel it would be very difficult for them to actually see all of the underpinning that allows us to know how successful it's been.

There were clearly identifiable risks in relation to the school being judged negatively 
against standard criteria (Perryman 2006; Lumby 2009). At the time, the school drew $90 \%$ of its pupils from working class areas, half of which were in the top $2 \%$ of deprived areas in the country. In this context, the distinction between attainment and progress was important:

Our results are okay. ... The only one of the issues is of course some of the work that's done out there is registering attainment rather than the progress of the students. ... Well we hope to benefit better from showing progress ... But, yeah, I mean, the results have been impressive. ... It doesn't help when goalposts keep changing.

There was a feeling though that what the school was doing was right for its students:

We're strong believers in the reasons behind putting our curriculum in place which was to meet the needs of our community and our students. ... we have the courage of our convictions and we are confident behind the idea of putting together a curriculum package for our students that meets the needs of our students and although that might not be of political favour it's surely the right thing to do for our students ...

Nevertheless, the risk was real, and all eyes were on Year 9, who were to be the first cohort to reach GCSE in the new model:

... it's a brave decision to go against those ideas and principles that the government are saying in terms of league tables but we started this journey 10 years ago and it was the right journey for our students .... I do feel for the Year 9s at the moment because they are the ones that ... [ they're the guinea pigs?] Yeah. ..... I can't wait to get to the end game, to the finish, if there is one (laughs).

This aside turned out to be somewhat prophetic: as we have shown, the staff were very positive about the changes, and were enthusiastic about their potential impact on the educational futures of highly disadvantaged students in terms of their developing control over their own learning, but the culture of performativity that drives innovation 
can also curtail it. Accountability policies can work against innovations such as that described here, leading ultimately to more 'teacher-centred, technocratic and performative' teaching approaches (Mausethagen 2013, 23).

Although the anticipated Ofsted inspection which occurred soon after our last visit praised the school's 'visionary approach' and 'exemplary tracking methods', exhorting it to continue to work towards students' involvement in their own learning, it also described the 'overall effectiveness', 'achievement' and 'quality of teaching' of the school as only 'satisfactory' ${ }^{3}$. It cited various concerns including a need to increase opportunities for discussion, debate and team problem-solving, to ask students more challenging questions and to maintain pace when students were working independently. Although this inspection potentially suggested that the school should continue on the same trajectory and improve the enactment of its vision, there were two further major drivers of events the following year. Firstly, a new head teacher was appointed, who did not share the aims of the innovation; following a six-week review, he concluded that there needed to be a return to a conventional system as soon as possible. Secondly, as he had predicted, there were disappointing GCSE results of just $24 \%$ achieving 5 Grades $\mathrm{A}^{*}$ to $\mathrm{C}$ including English and mathematics (14\% below the national average) later that year for the students who had been in Year 9 at the time of our visits, and who were the first cohort to experience the system innovation. These summative measures took precedence in the world of accountability, superseding the less easily measured object of independent learning. They provided the final catalyst for the school's reversion to a traditional system in the following academic year, dispensing with the thematic curriculum, rebuilding classrooms to replace open plan learning spaces, and introducing

\footnotetext{
${ }^{3}$ Ofsted uses a 4-point grading system in which 1 is outstanding, 2 is good, 3 is satisfactory and 4 is inadequate. A grade of 3 indicates that re-inspection might take place earlier than normal in the cycle.
} 
timetabling to replace the student booking system. Competing hard with its neighbours in its new status as a state-funded independent academy, the school's focus on GCSE results reflects the weight of the education market place.

\section{Conclusion}

Our focus on contradictions in this paper has highlighted a major issue in school innovation: an insistence on progress as indicated by what can be easily measured inevitably weakens the possibility of initiating changes that take time to develop such as different student relationships to learning. Our theoretical framework has revealed how the implementation of structural changes do not on their own lead to fundamental change; innovation depends on transformational learning which results from the inevitable contradictions which arise through attempts to change deeply embedded educational systems. Unfortunately, it is also commonplace that learning outcomes dip at some point in an innovation lifecycle (OECD 2013), although this can be avoided if additional resources and/or actions to counteract the negative impacts of experimentation are made available (Leadbeater 2008). A similar pressure to that felt by our school is also reported by Leadbeater (2008, 50): two schools involved in innovation projects 'had to put extra effort into improving exam results, in the short term, to win the time and space for further innovation'.

The aim of preparing students to be independent and deep learners to give them a better chance of success in the future was admirable. Given their backgrounds and the school's context however, the risks were high. Perhaps such a venture may have reached a successful conclusion in a different context. Perhaps it was ahead of its time and similar systems may be developed in the not too distant future. Indeed, the 2014 edition of the NMC Horizon Report K-12 focussing on trends, challenges and emerging 
technologies likely to have an impact on educational systems suggests that in five years' time there will be a movement to rethink how schools work with an increase in projectbased, cross-curricular approaches, and more flexible timetabling (Johnson et al. 2014). In conclusion, we suggest that the pressures of accountability meant that the school was unable to resolve the historically embedded contradictions between a culture of performativity and the new school object of producing the 'rounded student' capable of independent and connected learning. Consequently, it was equally unable to realise its innovative vision, since 'any model for the future that does not address and eliminate those contradictions will eventually turn out to be nonexpansive' (Engeström 1999, p35). 


\section{References}

Ball, S. J. 2003. "The teacher's soul and the terrors of performativity". Journal of Educational Policy 18 (2): 215-28.

Ball, S. J., and Olmedo, A. 2013. "Care of the self, resistance and subjectivity under neoliberal governmentalities". Critical Studies in Education 54 (1): 85-96.

Brown, K., and Cole, M. 2002. "Cultural Historical Activity Theory and the Expansion of Opportunities for Learning after School". In Learning for life in the $21^{\text {st }}$ Century, edited by G. Wells, and G. Claxton, 225-238. Oxford: Blackwell.

Daniels, H. 2008. Vygotsky and Research. Routledge, Abingdon

DfES (Department for Education and Skills). 2004. Building Schools for the Future: A new approach to capital investment. Annesley, UK: DfES. http://dera.ioe.ac.uk/7614/1/DfES\%200218\%20200MIG467.pdf

Engeström, Y. 1987. Learning by Expanding: An Activity - Theoretical Approach to Developmental Research. http://lchc.ucsd.edu/mca/Paper/Engestrom/expanding/toc.htm

Engeström, Y. 1999. "Activity theory and individual and social transformation”. In Perspectives on Activity Theory. Learning in Doing: social, cognitive, and computational perspectives, edited by Y. Engeström, R. Miettinen, and R.L.Punmäki, 19-38. Cambridge: Cambridge University Press.

Engeström, Y. 2001. "Expansive Learning at Work: toward an activity theoretical reconceptualization”. Journal of Education and Work 14 (1): 133-56.

Exley, S. and Ball, S. J. 2013. “Neo-liberalism and English education”. In Neoliberal Education Reforms: A Critical Analysis, edited by D. Turner and H. Yolcu, 13-31. London: Routledge.

Gewirtz, S., Ball, S. J. and Bowe, R. 1995. Markets, Choice and Equity in Education 
Milton Keynes: Open University Press

Gilbert, C., August, K., Brooks, R., Hancock, D., Hargreaves, D., Pearce, N., Roberts, J., Rose, J., and Wise, D. 2006. 2020 vision: Report of the Teaching and Learning by 2020 Review Group. Annesley, UK: DfES.

Hamdan, N., McKnight, P., McKnight, K., and Arfstrom, K.M. 2013. A review of flipped learning. Flipped Learning Network, Pearson, and George Mason University.http://www.flippedlearning.org/cms/lib07/VA01923112/Centricity/Do main/41/LitReview_FlippedLearning.pdf

Hargreaves, D. 2004. Personalising Learning. London: SSAT.

Hargreaves, D. 2006. Deep Experience 1. London: SSAT.

Hargreaves, D. 2007. System Redesign 1. London: SSAT.

Hartley, D. 2007. "Personalisation: the emerging 'revised' code of education?" Oxford Review of Education 33(5): 629-642.

Johnson, L., Adams Becker, S., Estrada, V., and Freeman, A. 2014. NMC Horizon Report: 2014 K-12 Edition. Austin, Texas: The New Media Consortium.

Keddie, A. 2013. "Thriving amid the performative demands of the contemporary audit culture: a matter of school context". Journal of Education Policy 28 (6): 750-766.

Kutti, K. 1996. "Activity Theory as a Potential Framework for Human-Computer Interaction Research". In Context and consciousness: Activity Theory and HumanComputer Interaction, edited by B. A. Nardi, 17-44. Cambridge, MA: MIT Press.

Leadbeater, C. 2006 "The future of public services: Personalised learning”. In Schooling for tomorrow: Personalising education, 101-114. Paris: OECD.

Leadbeater, C. 2008. What's next? 21 ideas for 21st century learning. London: The Innovation Unit.

Lumby, J. 2009. "Performativity and identity: mechanisms of exclusion". Journal of 
Education Policy 24 (3): 353-369.

Maguire, M., Ball, S. J., and Braun, A. 2013. "What ever happened to...? 'Personalised learning' as a case of policy dissipation”. Journal of Education Policy 28 (3): 322338.

Mahony, P., Hextall, I., and Richardson, M. 2011. “'Building Schools for the Future': reflections on a new social architecture". Journal of Education Policy 26 (3): 341360.

Mausethagen, S. 2013. "A research review of the impact of accountability policies on teachers' workplace relations". Educational Research Review 9: 16-33.

Meyer, B., Heywood, N., Sachdev, D., and Faraday, S. 2008. Independent learning: Literature Review. Annesley, UK: Department for Children Schools and Families. https://www.gov.uk/government/uploads/system/uploads/attachment_data/file/22 2277/DCSF-RR051.pdf

Miliband, D. 2006. "Choice and voice in personalised learning”. In Schooling for tomorrow: Personalising education, 21-30. Paris: OECD.

Mørch, A.I., Nygård, K.A, and Ludvigsen, S.R. 2010. “Adaptation and generalisation in software product development". In Activity Theory in Practice: Promoting learning across boundaries and agencies, edited by H. Daniels, A. Edwards, Y. Engeström and S.R. Ludvigsen, 184-206. London and New York: Routledge.

OECD (The Organisation for Economic Co-operation and Development) 2013.

Innovative Learning Environments. Paris: OECD.

http://dx.doi.org/10.1787/9789264203488-en

Perryman, J. 2006. Panoptic performativity and school inspection regimes: disciplinary mechanisms and life under special measures. Journal of Education Policy, 21 (2), $147-161$. 
Piattoeva, N. 2015. Elastic numbers: national examinations data as a technology of government. Journal of Education Policy, 30(3), 316-334.

QCA (Qualifications and Curriculum Authority) 2007. The New Secondary Curriculum:

What has changed and why. London: QCA. http://dera.ioe.ac.uk/6564/

Ranson, S. 2008. "Re-constituting Education Governance for Cosmopolitan Society". In Transforming Learning in Schools and Communities, edited by B. Lingard, J. Nixon, and S. Ranson, 184-208. London: Continuum.

Riddell, R. 2013. "Changing policy levers under the neoliberal state: realising coalition policy on education and social mobility". Journal of Education Policy 28 (6): $847-863$

Troman, G. 2008. "Primary teacher identity, commitment and career in performative school cultures”. British Educational Research Journal 34 (5): 619-633.

Vygotsky, L. S. 1978. Mind in Society: the development of higher psychological processes. Cambridge, MA: Harvard University Press.

Whitty, G. 2010. "Revisiting School Knowledge: Some sociological perspectives on new school curriculae". European Journal of Education 45 (1): 28-45. 